\title{
Revisiting e-learning effectiveness: proposing a conceptual model
}

George Macgregor ${ }^{\mathrm{a}}$; James Turner ${ }^{\mathrm{b}}$

anformation Management \& Systems, Liverpool Business School, Liverpool John Moores

University, Liverpool, UK

${ }^{\mathrm{b}}$ Learning Innovation and Development, Liverpool John Moores University, UK

Corresponding author:

George Macgregor, Information Strategy Group, Information Management \& Systems, Liverpool Business School, John Foster Building, 98 Mount Pleasant, Liverpool John Moores University, Liverpool L3 5UZ. UK

Tel: $+44(0) 1512313823$

Email: g.r.macgregor@1jmu.ac.uk

Web: http://www.staff.ljmu.ac.uk/bsngmacg/ 


\title{
Revisiting e-learning effectiveness: proposing a conceptual model
}

\begin{abstract}
Purpose: The use of e-learning is largely predicated upon the assumption that it can facilitate improvements in student learning and therefore can be more effective than conventional techniques. This assumption has been supported by some in the literature but has been questioned by a continuing body of contrary or indifferent evidence. The purpose of this paper is to improve our theoretical understanding of the variables influencing e-learning effectiveness, the manner in which these variables have been studied to date, and to propose a suitable conceptual model of e-learning effectiveness to aid its evaluation.
\end{abstract}

Design/methodology/approach: The paper revisits and critically reviews major contributions to the e-learning effectiveness literature.

Findings: Owing to a variety of issues prevalent in the literature, it is clear that the variables influencing effectiveness are multifarious and few researchers impose adequate controls or factor them into research designs. Drawing on the work of Dewey (1938), Englebart (1962) and Kaplan (2002), a conceptual framework of e-learning effectiveness is proposed. This model maps out the key variables involved in the study of e-learning effectiveness and the interactions between variables.

Originality/value: It is anticipated that such a model will assist researchers in developing future evaluative studies which are both sufficiently robust and holistic in design. It is also hypothesised that studies designed using the conceptual model will be more likely to yield results corroborating the ability of e-learning to affect improvements in student learning.

Paper type: Conceptual paper/Literature review

Keywords: e-learning; e-learning effectiveness; conceptual models; research design

\section{Introduction}

E-learning has become a key focus of activity within pedagogical communities of practice. Teachers in Higher Education (HE) are increasingly harnessing e-learning approaches to provide flexible course delivery models capable of meeting the needs of part-time study and lifelong learners (Macdonald, 2004). The advantages of e-learning are frequently purported in the literature (Bell, 2007; Biggs, 2007; Clarke, 2004; Frederickson et al., 2005; Leung, 2003; Waterhouse, 2005) and are generally manifest in the Web. Such benefits include the ability to engage students in non-linear information access and synthesis; the availability of learning environments from any location and at any time; the ability for students to influence the level and pace of engagement with the learning process; and, increased opportunities for deploying disparate learning strategies, such as group discussion and problem-based or collaborative learning, as well as delivering interactive learning materials or learning objects (Frederickson et al., 2005). Various administrative and managerial benefits are also cited, such as cost savings over traditional methods (Twigg, 1999) and the relative ease with which teaching materials or courses can be revised (Leung, 2003). Although flexible course delivery remains a principal motivating factor, the use of e-learning is largely predicated upon the assumption that it can facilitate improvements in student learning and therefore can be more effective than conventional techniques. This assumption has been supported by some in the literature, but also remains subject to debate owing to a large body of contrary or indifferent evidence. 
Given the cross-disciplinary nature of e-learning, literature emanates from a number of academic disciplines, including pedagogy, educational psychology, and library, computer and information science. A common difficulty inherent to the literature from all disciplines is a lack of emphasis on robust evaluative studies. Frederickson et al. (2005) note the preponderance of 'hypothetical' literature published by exponents of e-learning. Such literature seeks to delineate the hypothesised benefits of e-learning through models that are based largely on pedagogical theory or anecdotal evidence. Whilst much of this literature has aided researchers in designing evaluative studies, there is a recognition that e-learning research has to become more rigorous in its design and execution if an improved understanding of e-learning effectiveness is to be realised (Bernard et al., 2004; Moller et al., 2008).

The mixed nature of e-learning effectiveness research is therefore what motivates this revisitation of the literature. Significant contributions to the literature will be critically reviewed in an attempt to arrive at an improved understanding of the current effectiveness of e-learning in HE with the intention that a conceptual model of e-learning effectiveness be proposed to aid its evaluation. Whilst the community is well served by e-learning models, no such model exists for the study of e-learning effectiveness. It is anticipated that future studies designed using such a conceptual model would be better designed and therefore more likely to yield results supporting the effectiveness of e-learning.

\section{E-learning effectiveness: revisiting the research landscape}

Rosenberg $(2001,28)$ defines e-learning as the "use of Internet technologies to deliver a broad array of solutions that enhance knowledge and performance". Three essential criteria are used by Rosenberg to give his definition greater specificity. These are that e-learning: is networked; is delivered to the learner via a computer using conventional Internet technologies; and, "focuses on the broadest view of learning - learning solutions that go beyond the traditional paradigms of training" (Rosenberg, 2001, 29). Rosenberg's definition is cited by many as a framework within which to conduct e-learning research (Liaw et al., 2007; Ruiz et al., 2006; Tavangarian et al., 2004) and aligns with alternative definitions in the literature (e.g. Catherall, 2005; Leung, 2003). For these reasons Rosenberg's definition of elearning will used throughout this paper.

\subsection{Pedagogical theory}

Many in the literature support the view that e-learning invokes constructivist principles (Bangert, 2004; Macdonald, 2004; McDonald, 2006) and those of social learning (e.g. Johnson and Johnson, 1991; Lave and Wenger, 2003) (McDonald, 2006). The constructivist model of learning maintains that learners actively construct their own meaning and knowledge from their experiences (e.g. experiential learning) (Kolb, 1984). In particular, Macdonald (2004) notes that e-learning supports a 'family' of related constructivist pedagogies, such as collaborative learning, activity-based learning, resource-based learning and problem-based learning. These provide improved opportunities for students to interact with learning activities. Students can construct their own conceptualisations and solutions to problems thereby enhancing their understanding. The constructivist approach to e-learning will tend to emphasise autonomous and self-directed learning; however, this is balanced by using aspects of interactivity and social learning to provide the scaffolding necessary to develop higher-order thinking and metacognition (Frederickson et al., 2005; Macdonald, 2004; Rennie and Mason, 2006; Stewart et al., 2007).

Predicated upon the aforementioned pedagogical theories, e-learning appears to lend itself to the fulfilment of these pedagogies, thereby improving student learning. For example, the interactivity and social learning required for problem-based or collaborative learning can easily be facilitated via shared networked spaces, asynchronous chat tools or wikis. For these 
reasons some educationalists consider the benefits of e-learning to be 'self-evident' and advocate the use of e-learning owing to its perceived effectiveness over traditional methods (Anderson, 2002; Clarke, 2004; Mason, 2002; Mason and Rennie, 2006; Oliver, 2002).

The evaluation of e-learning effectiveness has drawn parallels to earlier phases of related research, particularly research undertaken by Clark (1983). Clark's assertion that the delivery mechanism has little influence on the outcomes of instruction has found resonance in elearning research, where similar arguments are applied. More recently this assertion has been tested by a number of evaluative and experimental studies.

\subsection{Comparative studies}

Bernard et al. (2004) undertook a meta-analysis of selected research between 1985 and 2002, comparing the effectiveness of distance education and face-to-face tuition. They found little difference in the effectiveness of both approaches. Despite being a rigorously applied study, Bernard and his colleagues acknowledge that the weak design of the studies analysed mean that their findings can only be considered indicative. Indeed, much of the surveyed distance education and e-learning research was found to be of a low quality and did not follow robust scientific research designs, thus compromising the validity of their meta-analysis. At the very least, their research emphasises the need to review e-learning effectiveness studies individually.

A longitudinal study conducted by Piccoli et al. (2001) compared undergraduate students undertaking business related modules using a two group repeated measure experimental design. One group of students (treatment group) undertook module tuition entirely within a Virtual Learning Environment (VLE); the other (control group) was exposed to conventional face-to-face instructional techniques. E-learning effectiveness was measured by student performance in formative and summative assessment, as well as qualitative data gathered via end of term surveys and other forms of structured feedback. The Piccoli et al. findings suggest that e-learning is a feasible and effective alternative to conventional teaching techniques, providing students are afforded sufficient control over their learning process (i.e. 'learner control'). Performance outcomes of both the e-learning and traditional approaches were similar and no statistically significant differences could be found. Although the VLE students exemplified improved information and communications technology (ICT) skills as a result of their prolonged exposure to e-learning, they actually reported a lower level of satisfaction with the learning experience. This latter finding was attributed to glitches in the system design, but also to a lack of social interaction between students and teachers. Issues of learner control and social interaction continue to be a focus for researchers investigating low retention rates on e-learning-based courses and will assume more relevance later.

Piccoli et al.'s (2001) observance of methodological rigour and large group numbers means that their study is often cited as significant (Abraham, 2002; Hui et al., 2008); however, the composition of their student groups fails to follow strict experimental designs. Both groups were self-selecting thus introducing bias, as those students more favourably disposed to ICT would be expected to join the VLE group. Unfortunately, such problems of group composition have not been rectified in many subsequent studies. For example, Abraham (2002) conducted a similarly designed comparative study, measuring the effectiveness of delivering a business information systems course via traditional methods and via a VLE. Abraham found e-learning effectiveness to be similar to that of conventional teaching techniques. Abraham's use of self-selection is acknowledged, but is defended on the grounds that the experimental design follows established distance education research models.

One of the key difficulties in researching e-learning effectiveness is that student ICT efficacy can rarely be presupposed. An additional ethical concern - which seems to preclude random assignment - is engaging one group of students in a teaching mode that is potentially superior 
to another. For these reasons group self-selection becomes the default experimental model used by most e-learning effectiveness studies. Given the methodological rigour exemplified by Piccoli et al. (2001) and Abraham (2002), their findings are by no means rendered entirely invalid by self-selection. A variety of similarly designed studies undertaken in a range of varying educational contexts have arrived at comparable findings. For example, studies conducted by Wenger et al. (1999), Dutton et al. (2002), Fallah and Ubell (2000), Johnson et al. (2000), Leung (2003) and Anakwe (2008) have found no statistically significant difference in group performances. Interestingly, Dutton et al. (2002) found that e-learners achieved better exam scores; but this improvement was not found to be statistically significant when all course assessments were measured. Frederickson et al. (2005) also found no statistically significant difference in group performances but found student satisfaction with e-learning to be lower than those students exposed to traditional methods. This latter finding corroborates those of Johnson et al. (2000) who also found greater student satisfaction in those students exposed to traditional teaching methods.

Much of the aforementioned research takes the view that e-learning has no negative effect on learning thereby justifying its extended use in distance education or in blended learning. Though more positive empirical research is limited, it is not uncommon. Such research infers that e-learning can achieve better learning in students and can therefore be more effective. Liu et al. (2007) undertook a comparative study, employing the use of a treatment and control group. Their study differs to others owing to the spread of research instruments deployed and the variety of research variables analysed. Group composition also differs and - although not randomly assigned - participants were not self-selected. Liu et al. also control for low ICT and VLE efficacy among students by providing pre-test orientation sessions. The outcome of the study found the group receiving e-learning to achieve a better learning performance than the control group. Supplementary findings included improved student satisfaction and faster problem solving skills among the e-learning group.

Largely positive results were also reported by Hui et al. (2008) in their study of undergraduate language students. Their study explicitly used Kolb's (1984) experiential learning model and sought to assess the effectiveness of e-learning within a blended learning context, comparing a treatment group (i.e. students exposed to face-to-face teaching and elearning) with a control group using face-to-face methods only. Their results suggested that the treatment group significantly improved students' acquisition of language vocabulary, but negatively affected listening comprehension.

Zhang (2005) conducted a series of experiments to determine the effectiveness of e-learning and specifically the role of interactivity in facilitating effectiveness. Controlling for ICT and VLE efficacy, Zhang randomly assigned students to one of three treatment groups (fully interactive, less interactive and traditional classroom). The study found that those students exposed to e-learning with a high degree of interactivity significantly improved their learning performance and satisfaction with the course. Zhang's research is interesting owing to the use of three groups, thus permitting the study of variables within e-learning which can influence effectiveness (i.e. learner control). Zhang's findings therefore suggest that higher levels of interaction permit flexibility in student learning, thus students have greater control over learning and are likely to engage with it at deeper cognitive levels (e.g. ability to revisit difficult material, random content access, etc.).

\subsection{Learner control, social interaction, learning styles}

The importance of learner control within e-learning is summarised by a number of researchers (e.g. Liaw et al., 2007; Liu et al., 2007; Piccoli et al., 2001; Thorpe and Godwin, 2006). Laurillard (2003) also conceptualises learner control within her conversational framework classification scheme for the effective use of learning technologies, specifically within her 'reflective' class. Learner control is underpinned by several sub-theories, including 
motivation theory, attribution theory and information processing theory (Piccoli et al., 2001). By employing these theories proponents argue that students will achieve better learning if they are allowed to influence their pace of learning (Liu et al., 2007). Control can instil feelings of competence within the learner and promote greater interest in the learning activity being undertaken. This in turn facilitates learner reflection, higher order thinking and stimulates metacognition. It is noteworthy that recent developments in adaptive e-learning are in part motivated by a desire to improve learner control and to increase interest in learning activities (Blazic et al., 2007; Chiu et al., 2008; Challis, 2005; Scalise et al., 2007).

As well as the work of Zhang (2005), the hypothesised benefits of learner control have been corroborated by a number of other studies. Liu et al.'s (2007) comparative study concluded that high levels of learner control was the principal factor in facilitating e-learning effectiveness, better learning achievement among students, and metacognition. Such findings have been supported by Liaw et al. (2007) and Liaw (2008). They present research using a variety of theoretical and survey instruments to assess the effectiveness of e-learning (specifically via Blackboard), as well as student attitudes and satisfaction. They note a number of factors as being important in determining e-learning effectiveness, including the degree to which learners can control their learning. Nevertheless, it is clear that the level of learner control is something that requires careful consideration. Piccoli et al.'s (2001) seminal comparative study hypothesised that high levels of learner control would improve elearning effectiveness; however, whilst high learner control did not impact negatively on effectiveness, they discovered that too much freedom in learner control actually disorientated and frustrated learners, thereby reducing satisfaction with e-learning. This has led to the emergence of navigation support tools to aid learning but also to improve retention, particularly within distance education contexts (Bolman et al., 2007).

Promoting learner control is clearly a significant factor influencing e-learning effectiveness and is consistent with the theories of constructivism, as discussed earlier. Such learner autonomy has to be balanced by social learning, and the family of constructivist pedagogies outlined by Macdonald (2004) note the importance of collaborative and problem-based learning. The pedagogical benefits of group learning have been well expounded elsewhere (e.g. Johnson and Johnson, 1991); but are worthwhile summarising. It can promote improved critical thinking, develop generic management competencies, allow the exchange of knowledge or synthesise learner expertise, and stimulate deep learning (Hassanien, 2007).

Thorpe and Godwin (2006) report on the importance of social interaction within e-learning and numerous researchers identify opportunities for social interactivity in e-learning effectiveness (e.g. Abras et al., 2005; Arbaugh, 2001; Connor, 2003; Hui et al., 2008; Jiang et al., 2006; Johnson et al., 2000; Johnson et al., 2008; Kennewell et al., 2008; McConnell, 2002; Pilkington and Walker, 2004; Sclater and Bolander, 2004; Webb et al., 2004). For example, Johnson et al. (2008) undertook an empirical examination of the factors contributing to the creation of successful e-learning environments and concluded that high levels of peerto-peer interaction were required to ensure that the benefits of conventional group learning techniques were replicated ("social presence"). Similarly, Arbaugh (2001) found that reducing the 'social distance' of students within e-learning environments was a positive predictor of student learning and satisfaction. These conclusions corroborate the theoretical importance ascribed to group and social learning (e.g. self-directed learning bolstered by the social scaffolding necessary to develop higher-order thinking and metacognition). Even where positive e-learning effectiveness results have been found, sufficient social interaction with online tutors has been found to be an important predictor of student satisfaction (Maki et al., 2000). Such findings would also appear to support the current enthusiasm for social networking technologies within e-learning contexts (e.g. Baird and Fisher, 2007; Hall, 2009).

The importance of social interactivity as a factor in e-learning effectiveness therefore appears incontrovertible and well understood; yet, few of the recent comparative studies reporting 
indifferent results adequately control for it or appear aware of its significance. Participants are often studied in linear environments offering few opportunities for collaborative learning, and in qualitative feedback students often report feeling 'disengaged' or 'isolated'. This is in contrast to research reporting high e-learning effectiveness, in which sufficient controls are implemented (e.g. Hui et al., 2008; Liu et al., 2007). Even the emergence of social networking technologies - a development which appears to support key pedagogical principles (Dalsgaard, 2008) - has been treated to limited evaluative scrutiny within the context of improving learning.

Since social learning is an important factor in e-learning effectiveness it has been hypothesised that personal learning styles may also influence the effectiveness of e-learning (Clarke, 2004). Twigg (2001) summarises a variety of research and opinion work noting the importance of learning styles within online and distance learning contexts; but such suppositions have been rejected by more recent work. Aragon et al.'s (2002) highly controlled empirical study examined the relationship of learning style preferences to learning performance and found no significant differences in the learning styles of e-learners and those exposed to conventional teaching methods. More recently, Wang et al. (2006) studied the effects of formative assessment and learning styles on student performance within an elearning environment. Their results were inconclusive, but suggested that learning style may yet be a significant effectiveness factor. They recommended further research exploring how e-learning systems could be designed or adapted to better accommodate disparate learning styles. Such research is currently the preserve of adaptive e-learning system work (Scalise et al., 2007).

\subsection{System design, usability, information literacy}

The role of e-learning system design has emerged as a possible determinant in effectiveness (Waterhouse, 2005). Effectiveness research undertaken by Hui et al. (2008), McPherson and Nunes (2008), and Liaw et al. (2007) has concluded that design warrants further research. Effectiveness research can be more specific, with Littlejohn et al. (2008) reporting on the attributes of learning objects (i.e. e-learning resources), noting the multifarious factors that can influence their efficacy in learning, as well as the technical issues relating to their deployment in the 'classroom'.

The theory underpinning system design dictates that learners who perceive the system to have positive characteristics will not only find it easier to use and more useful in learning but will also have a greater intention of using it. Pituch and Lee (2006) have confirmed this theory. They conducted a study which sought to explain students' intention of using an e-learning system based on alternative design models. Collecting data from 260 students via a survey instrument, they confirmed the hypothesis that design impacts on effectiveness, noting the importance of usability and communication tools. The role of system design in e-learning effectiveness has motivated more specific work examining aspects such as usability. The foundation of usability research in e-learning tends to employ ideas formulated by usability expert, Jakob Neilsen (2000), and suggests that system usability influences system learnability, user satisfaction and ergo task completion (Paas and Firssova, 2004). Humancomputer interaction (HCI) is also significant and the work of Schneiderman (1999) notes the role of usability in promoting user creativity in a wide range of information tasks. Since the emergence of these works, Rhee et al. (2006) found the Web interfaces of e-learning environments to be a significant determinant in e-learning efficacy. They also noted the requirement for greater consistency between interface designs to promote deeper levels of elearning engagement among students, particularly skilled students that have developed expectations of usability. In a more complex study, Blazic et al. (2007) established a correlation between e-learning system usability and learnability. Such work has stimulated others to disseminate widely about the importance of such factors in e-learning efficacy (e.g. Phipps and Kelly, 2006; Cooper et al., 2007). 
Linked to usability are theories of user-centred design and Information Architecture (Morville, 2005). Germane to these philosophies is organising and structuring information within systems to aid users' ability to retrieve, synthesise and exchange information. Such factors become especially significant when systems employ interactive or reflective classification characteristics (Laurillard, 2003), or employ constructivist pedagogies such as collaborative or problem-based learning (Macdonald, 2004). For example, McGill et al. (2005) report on an e-learning environment for design engineering students. Their system employed the use of shared workspaces and wikis to foster a collaborative design process; yet, the large amount of information generated by students created 'information overload' and compromised the effectiveness of the system as a learning tool. To facilitate information reuse, synthesis and exchange, it was necessary for students and system technologists to implement hierarchical file structures, deploy metadata, and index and organise information via subject taxonomies. Only by doing this could students work more effectively and benefit from collaborative learning.

Even if systems are made more conducive to interaction, learners may still encounter difficulties deriving maximum benefit from them. A basic level of ICT efficacy has been recognised for some time (e.g. Clarke, 2004) and - as noted earlier - is a major stumbling block in the design of experimental studies. However, Macdonald (2004) points to the need for students to acquire a basic competency in information literacy. The research area of information literacy is well established in library and information science (e.g. Andretta, 2005; Eisenberg et al., 2004) and has consequent links with educational theory (Macdonald, 2004). Information literacy essentially pertains to the ability of learners to identify an information need, then to locate, retrieve, evaluate, organise and use information. Students' ability to demonstrate such competencies continues to be important if students are not participating in e-learning, but is fundamental if they are. Without adequate information literacy skills, Macdonald (2004) questions whether e-learners have the critical and analytical abilities to function effectively as a self-directed learner within an information rich e-learning environment. Research and development work undertaken by a number of e-learning researchers have found it necessary to embed information literacy instruction within taught sessions to improve e-learning effectiveness (Breslin et al., 2007; McGill et al., 2005; Secker, 2004; Wang, 2007). As e-learning environments develop to offer more advanced tools, researchers have also recognised that students will have to acquire a suite of sophisticated information literacies (Macgregor and McGill, 2005).

\section{Discussion and conceptual model}

\subsection{Effectiveness variables}

It is clear that evidence supporting the effectiveness of e-learning in HE teaching and learning remains debatable. A number of studies have arrived at indifferent conclusions and support the view that e-learning is at least as effective as traditional teaching methods, but not more effective. This continues to support the 'no significant difference' phenomenon originally posited by Russell (2009). However, many of these studies exemplified a lack of methodological rigour (e.g. group self-selection) and all failed to control for some of the most basic variables hypothesised to influence effectiveness (e.g. social interaction, learner control, etc.). By contrast, those studies which have been more holistic in the treatment of variables in their methodological designs have found e-learning to be more effective (i.e. Liu et al., 2007; Hui et al., 2008; Zhang 2005). These positive results could be attributed to the fact that elearning, as an area of study, is maturing; bringing with it an improved understanding of the variables influencing e-learning effectiveness.

Although positive research tends to employ greater control over variables, it fails to control for all the factors considered - both empirically and theoretically - to influence whether e- 
learning will be effective or not. Frederickson et al. (2005) have suggested that the theoretical understanding of e-learning has been exhausted and call for a greater emphasis on empirical research; yet it is precisely because a lack of theoretical understanding exists that invalid empirical studies have been designed. It is evident that the variables influencing elearning effectiveness are multifarious and few researchers impose adequate controls, factor any of them into research designs, or are cognisant of their significance or existence. Such variables include: level of learner control; social interactivity; learning styles; e-learning system design; properties of learning objects used; system or interface usability; ICT and information literacy skills; and, the manner or degree to which information is managed within the e-learning environment (e.g. Information Architecture). It could be concluded that no valid e-learning effectiveness research has ever been undertaken since no study has yet attempted to control for them all.

From a research methods perspective it is possible to describe these factors as extraneous variables. They are variables that threaten internal validity since they have been shown in the reviewed literature to influence e-learning effectiveness. Their consideration by researchers, either by decreasing or controlling their influence, is therefore essential to minimise error. However, labelling all of these variables as simply extraneous is problematic owing to the difficulties we have in delineating an e-learning 'system' (i.e. the independent variable), changes in which affect student learning (i.e. the dependent variable). This is specifically problematic for variables such as social interactivity or system design and usability, both of which could be considered extraneous but which are really subsumed by the e-learning system itself. In these examples each could be considered component variables (i.e. components of the larger independent variable - the e-learning system). Irrespective of how these variables are labelled it is clear that their existence and interactions have to be factored into effectiveness research if such work is to be accurate and valid.

\subsection{Conceptual model: e-learning effectiveness}

The area of e-learning is well served by a variety of conceptual models, each proposed by researchers to better understand particular aspects of e-learning. Laurillard's (2003) frameworks, for example, have been instrumental in improving theoretical understanding of using technologies in education. However, there exists no such model for the study of elearning effectiveness. Since a lack of theoretical understanding appears to be inhibiting elearning effectiveness research, the present authors suggest the use of a conceptual model to aid researchers in comprehending these variables and the manner in which they interact. Use of an appropriately designed conceptual model could prove useful to those researchers wishing to undertake the 'holistic' studies described above as it would enable disparate variables to be factored into research designs and - depending on the nature of the study - for specific variables to be controlled.

The use of conceptual models (or frameworks) is fundamental to research and underpins the philosophy of science and logical inquiry (Dewey, 1938). Such models are often cited as a precondition of theory and hypothesis formulation, as well as research design itself (Kaplan, 2002), and are often based on a reflective review and synthesis of existing work (Shields and Tajalli, 2006). According to Englebart (1962), conceptual models can provide 'orientation' as to the important factors of the system under investigation, their relationships and interactions, and the nature of any changes in these factors and their relationships and how these might affect the functioning of the system. A conceptual model may also highlight promising areas for further research or aid in the identification of suitable research methodologies. The idea of conceptual models providing 'orientation' for the researcher is manifest in their use within some communities of practice as an 'orienting strategy'; "what concepts [for study] it should include and about how those concepts should be linked" (Wagner and Berger, 1985, 700). 
Kaplan $(2002,273)$ explores the functions of models within scientific inquiry generally and provides a specific typology of models. These include physical, semantical, interpretive and formal models. Of relevance to us are formal models. These are models which afford a degree of flexibility in the conceptualisation of the model and its constituent parts, and which rely on the deductive method. Within formal models it is possible to deliberately ignore specific variables (even if they are generally considered essential to the phenomenon under study) and extricate theory "from the irrelevancies necessarily involved in any concrete embodiment of the structure" (273). Formal models can assist researchers in determining what constituent parts might be relevant in the study of a particular phenomenon and therefore constitute models of a theory.

$$
<<<<\text { Take in Figure 1 } 1>>>>
$$

\section{Figure 1: Conceptual model of factors in e-learning effectiveness}

On the basis of the key variables noted in the literature and the observations gained therein, it is possible to propose a rudimentary conceptual model of e-learning effectiveness (Figure 1). The benefit of this model is that it identifies the important factors relevant in evaluating elearning effectiveness and characterises the nature of the relationships between these factors. Noting the theoretical work of Dewey (1938) and Englebart (1962) outlined above, the conceptual model maps out the relations between 'ideational and conceptual matter' thus providing the necessary 'orientation' for future evaluative e-learning work (see Englebart, 1962). Additionally, the model conforms to Kaplan's (2002) characterisation of formal models by essentially providing a model of a theory (i.e. that e-learning can facilitate improved learning in students). Recall also that formal models assist researchers in determining what constituent parts might be relevant in the study of a particular phenomenon. This aligns with our intention of proposing a conceptual model which aids the researcher in the study of e-learning effectiveness.

It is anticipated that this conceptual model will assist researchers in developing future evaluative studies which are both sufficiently robust and holistic in design. It could consequently be hypothesised that those studies controlling for the aforementioned variables in their studies are more likely to yield results corroborating the ability of e-learning to affect improvements in student learning, as per some existing research (e.g. Liu et al., 2007).

It is also possible to use the model to support modular approaches to the study of e-learning effectiveness. For example, the model will support those researchers wishing to better understand or measure specific aspects of e-learning. Learner control is arguably the best example of this, particularly since we remain unclear as to the levels of learner control required to foster e-learning effectiveness. Too much learner control can disorientate learners; too little precludes learner reflection, higher order thinking and metacognition. Our current understanding is therefore limited to knowing that learner control is an important determinant of effectiveness. Controlling for all other variables during such studies will permit researchers to be more conclusive about the nature of the factor(s) under investigation since researchers can be confident that error has not been introduced by unknown variables. This will also support the study of any underlying factors influencing specific variables.

\subsection{Overview of model}

As Figure 2 illustrates and the arrangement of the model suggests, there are two main nodes: node $A$, and; node $B$. Node $A$ primarily focuses on external variables influencing the student and the efficacy of the student learning experience within the e-learning environment. Node $B$ focuses on the internal forces affecting e-learning efficacy. These nodes are connected by the 'learner control' arrow (Figure 1) which denotes the two-way interaction afforded by the student-system relationship; but also denotes a significant variable of effectiveness as being the degree of student learning control permitted. 


\section{Figure 2: Main nodes of the conceptual model, connected in Figure 1 by 'learner control'.}

Looking more closely at node $A$ (Figure 1), we can observe that for e-learning to be effective the student is required to be at the centre of a wider online community. Since social distance has been found to affect student learning and satisfaction, an unspecified degree of social interactivity is necessary to facilitate the benefits of social learning and to obviate student isolation. The variables (or 'forces') exerting influence over student learning within the environment can also influence e-learning effectiveness and can be observed above and below the node via two arrows within cloud shapes. Many of these variables will tend to be external forces (i.e. extraneous variables) which can significantly affect e-learning effectiveness. This is reflected in the broken lines of the cloud shapes. For example, students are often assumed to have an appropriate level of ICT and information literacy such that they can maximise their experience as e-learners; yet, we have noted that that the critical and analytical abilities of students to function effectively as self-directed e-learners within an information rich elearning environment are highly variable and - within an experimental context - need to be controlled. Although ICT and information literacy are considered to be external forces, we learned earlier in this paper that it is possible for teachers or learning technologists to embed the necessary orientation into curriculum design. The broken arrow feeding back from node $B$ to node $A$ denotes this possible relationship (see Figure 1).

The capacity for learning styles or assessment strategy to be shaped in a similar way is obviously unachievable for the former since this is something that the student brings to the learning event. Nevertheless, it remains something that has to be controlled in the evaluative research design. For the latter it remains problematic owing to the level of alignment required between learning, instruction and assessment (Biggs, 2007). Perceptions of assessment may also vary owing to students' own particular learning style. Even where learning and assessment environments have been modified to align with constructivist principles, scholars have found fewer students employing deep learning approaches and even fewer students perceiving the assessment to be designed to promote deep learning (Segers et al., 2006). For these reasons assessment remains predominantly an external and extraneous concern within the conceptual model.

Node $B$ focuses on the internal forces influencing the effectiveness of e-learning: system design and usability, information architecture, interactivity, and learning object quality. These are variables over which the tutor or learning technologist can exert some influence, often because these variables are systems related (i.e. component variables). The ability of the teacher or learning technologist to influence these component variables can be observed by their inclusion within node $B$ as cloud shapes (with solid lines). The nature of the node $B$ variables have been delineated in previous sections, however it is important to note that although they reside within node $B$ and constitute internal forces, they are autonomous of each other and therefore require attention on the part of the researcher when conducting effectiveness studies. As we noted earlier for example, system usability has been demonstrated to influence system learnability, user satisfaction and therefore task completion. Consistent with usability generally, there is also a requirement for greater interface consistency to promote deeper levels of e-learning among students, particularly proficient elearners that have developed specific usability expectations.

\section{Conclusion}

In this paper we have revisited significant examples of the e-learning effectiveness research literature. A number of comparative studies have arrived at indifferent conclusions and support the view that e-learning is at least as effective as traditional teaching methods, but not 
more effective. However, based on our critical review and synthesis of the literature, a conceptual model of e-learning effectiveness has been proposed. As with all conceptual models, it is expected that other researchers will critique and/or augment the model as our understanding of e-learning matures. This is consistent with the evolutionary nature of conceptual models. It is nevertheless hoped that such a conceptual model will aid comprehension of the significant variables affecting e-learning efficacy and the manner in which they interact. It is also expected that such a model will assist researchers in developing future evaluative studies in which all variables are factored into research designs, or to assist researchers in better exploring specific facets of e-learning effectiveness, such as the extent to which social interactivity or learner control is significant. This is both essential to better understand the nature of e-learning, but also to justify institutional investment in e-learning generally. It is hypothesised that research employing the model in study design - and adhering to good research methods practice - will be more likely to yield positive e-learning effectiveness results. Future research should therefore seek to deploy the model in an experimental context to assess its provenance and it is the intention of the current authors to do so.

\section{References}

Abraham, T. (2002), "Evaluating the virtual Management Information Systems (MIS) classroom”, Journal of Information Systems Education, Vol. 13 No 2, pp. 125-134.

Abras, C., Ozok, A. and Preece, J. (2005), "Research methods for validating and deriving guidelines for e-learning online communities", Interactive Technology and Smart Education, Vol. 2 No. 4, pp. 207-219.

Anakwe, B. (2008), “Comparison of student performance in paper-based versus computer-based testing”, Journal of Education for Business, Vol. 84 No. 1, pp. 13-17.

Anderson, T. (2004), “Toward a theory of online learning”, in Anderson, T. and Elloumi, F. (Ed.), Theory and practice of online learning, Athabasca University, Athabasca, pp. 33-60.

Andretta, S. (2005), Information literacy: a practitioner's guide. Chandos Publishing, Oxford.

Aragon, S.R., Johnson, S.D. and Shaik, N. (2002), "The influence of learning style preferences on student success in online versus face-to-face environments", American Journal of Distance Education, Vol. 16 No. 4, pp. 227-244.

Arbaugh, J.B. (2001), "How instructor immediacy behaviors affect student satisfaction and learning in Web-based courses”, Business Communication Quarterly, Vol. 64 No 4, pp. 42-54.

Baird, D. and Fisher, M. (2007), "Neomillennial user experience design strategies: Utilizing social networking media to support "always on" learning styles", Educational Administration Abstracts, Vol. 42 No. 3, pp. 5-32.

Bangert, A.W. (2004), "The seven principles of good practice: a framework for evaluating on-line teaching", Internet and Higher Education, Vol. 7 No. 3, pp. 217-232.

Bates, T. and Bates, T. (2005), Technology, e-learning and distance education. RoutledgeFalmer studies in distance education. Routledge, London.

Bell, J. (2007), “E-learning: your flexible development friend?” Development and Learning in Organizations, Vol. 21 No. 6, pp. 7-9.

Bernard, R.M., Abrami, P.C., Lou, Y., Borokhovski, E., Wade, A., Wozney, L., Wallet, P.A., Fiset, M. and Huang, B. (2004), "How does distance education compare with classroom instruction? A meta-analysis of the empirical literature", Review of Educational Research Vol. 74 No. 3, pp. 379-439.

Biggs, J. (2007), Teaching for quality learning at university, 2nd. ed. Society for Research into Higher Education and Open University Press, Berkshire.

Blazic, B.J., Law, E.L.-C and Arh, T. (2007), “An assessment of the usability of an internet-based education system in a cross-cultural environment: the case of the Interreg Crossborder Program in central Europe", Journal of the American Society for Information Science and Technology, Vol. 58 No. 1, pp. 66-75. 
Bolman, C., Tattersall, C., Waterink, W., Janssen, J., Berg, R. van den, Es, R. van and Koper, R. (2007), "Learners' evaluation of a navigation support tool in distance education", Journal of Computer Assisted Learning, Vol. 23 No. 5, pp. 384-392.

Breslin, C., Nicol, D., Grierson, H., Wodehouse, A., Juster, N. and Ion, W. (2007), "Embedding an integrated learning environment and digital repository in design engineering education: lessons learned for sustainability", British Journal of Educational Technology, Vol. 38 No. 5, pp. 805-816.

Catherall, P. (2005), Delivering e-learning for information services in higher education. Chandos Publishing, Oxford.

Challis, D. (2005). "Committing to quality learning through adaptive online assessment”, Assessment \& Evaluation in Higher Education, Vol. 30 No. 5, pp. 519-527.

Chiu, H.Y., Sheng, C.C. and Chen, A.P. (2008), "Modeling agent-based performance evaluation for e-learning systems", Electronic Library, Vol. 26 No 3, pp. 345-362.

Clark, R.E. (1983), "Reconsidering research on learning from media", Review of Educational Research, Vol. 53 No. 4, pp. 445-459.

Clarke, A. (2004), E-learning skills. Palgrave Macmillan, Basingstoke.

Connor, C. (2003), "Virtual learning and inter-professional education: developing computer-mediated communication for learning about collaboration", Innovations in Education and Teaching International, Vol. 40 No. 4, pp. 341-347.

Cooper, M., Colwell, C. and Jelfs, A. (2007), "Embedding accessibility and usability: considerations for e-learning research and development projects", ALT-J, Research in Learning Technology, Vol. 15 No. 3, pp. 231-245.

Dalsgaard, C. (2008), Social networking sites: Transparency in online education, 14th Congress of the European University Information Systems Organisation (EUNIS), Aarhus University, Aarhus, available at: http://eunis.dk/papers/p41.pdf (accessed 31 August 2009)

Dewey, J. (1938), Logic: the theory of inquiry. Allen \& Unwin, London.

Dutton, J., Dutton, M. and Perry, J. (2002), “How do online students differ from lecture students?”, Journal of Management Information Systems, Vol. 18 No 4, pp. 169-190.

Eisenberg, M., Lowe, C.A. and Spitzer, K.L. (2004), Information literacy: essential skills for the information age. Libraries Unlimited, Westport.

Englebart, D.C. (1962), Augmenting human intellect: a conceptual framework. Bootstrap Alliance, Fremont, CA, available at: http://www.bootstrap.org/augdocs/friedewald030402/augmentinghumanintellect/ahi62index.html (accessed 19 April 2009)

Fallah, M.H. and Ubell, R. (2000), "Blind scores in a graduate test: conventional compared with web-based outcomes", Asynchronous Learning Networks (ALN) Magazine, Vol. 4 No. 2, available at: http://www.aln.org/publications/magazine/v4n2/fallah.asp (accessed 19 April 2009)

Frederickson, N., Reed, P. and Clifford, V. (2005), "Evaluating Web-supported learning versus lecture-based teaching: quantitative and qualitative perspectives", Higher Education, Vol. 50 No. 4, pp. 645-664.

Hall, R. (2009), "Towards a Fusion of Formal and Informal Learning Environments: the Impact of the Read/Write Web", Electronic Journal of e-Learning, Vol. 7 No. 4, pp. 29-40.

Hassanien, A. (2007), “A qualitative student evaluation of group learning in higher education”, Higher Education in Europe, Vol. 32 No. 2, pp. 135-150.

Hui, W., Hu, P.J., Clark, T.H., Tam, K.Y. and Milton, J. (2008), "Technology-assisted learning: a longitudinal field study of knowledge category, learning effectiveness and satisfaction in language learning", Journal of Computer Assisted Learning, Vol. 24 No. 3, pp. 245-259.

Jiang, M., Parent, S. and Eastmond, D. (2006), "Effectiveness of Web-based learning opportunities in a competency-based program”, International Journal on E-learning, Vol. 5 No. 3, pp. 353-360. 
Johnson, R.D., Hornik, S. and Salas, E. (2008), “An empirical examination of factors contributing to the creation of successful e-learning environments", International Journal of Human Computer Studies, Vol. 66 No. 5, pp. 356-369.

Johnson, S.D., Aragon, S.R., Shaik, N. and Palma-Rivas, N. (2000), "Comparative analysis of learner satisfaction and learning outcomes in online and face-to-face learning environments", Journal of Interactive Learning Research, Vol. 11 No. 1, pp. 29-50.

Johnson, D.W. and Johnson, F.P. (1991), Joining together: group theory and group skills. Prentice-Hall International Inc, London.

Kaplan, A. (2002), The conduct of inquiry: methodology for behavioural science. Transaction, London. (Orig. pub. 1964).

Kennewell, S., Tanner, H., Jones, S. and Beauchamp, G. (2008), "Analysing the use of interactive technology to implement interactive teaching”, Journal of Computer Assisted Learning, Vol. 24 No. 1, pp. 61-73.

Kolb, D.A. (1984), Experimental learning: experience as the source of learning and development. Prentice-Hall, Englewood Cliffs.

Laurillard, D. (2003), Rethinking university teaching: a conversational framework for the effective use of learning technologies, 2nd ed. RoutledgeFalmer, London.

Lave, J. and Wenger, E. (2003), Situated learning: legitimate peripheral participation. Cambridge University Press, Cambridge.

Leung, H.K. (2003), "Evaluating the Effectiveness of e-Learning”, Computer Science Education, Vol. 13 No. 2, pp. 123-136.

Liaw, S.S. (2008), "Investigating students' perceived satisfaction, behavioral intention, and effectiveness of elearning: a case study of the Blackboard system", Computers and Education, Vol. 51 No. 2, pp. 864-873.

Liaw, S.S., Huang, H.M. and Chen, G.D. (2007), "Surveying instructor and learner attitudes toward e-learning", Computer and Education, Vol. 49 No. 4, pp. 1066-1080.

Littlejohn, A., Falconer, I., and McGill, L. (2008), "Characterising effective eLearning resources”, Computers and Education, No. 50 No. 3, pp. 757-771.

Liu, C.-H., Chiang, T.-C. and Huang, Y.-M. (2007), “Assessment of effectiveness of Web-based training on demand", Interactive Learning Environments, Vol. 15 No. 3, pp. 217-235.

Macgregor, G. and McGill, L. (2005), "Digital libraries and information literacy issues within virtual learning environments: an e-learning impasse?", paper presented at the Librarians' Annual Information Literacy Conference (LILAC), April 4-6, Imperial College, London, UK, available at: http://eprints.cdlr.strath.ac.uk/2334/01/MacgregorMcGill_LILAC2005.pdf (accessed 19 April 2009)

Maki, R.H., Maki, W.S., Patterson, M. and Whittaker, P.D. (2000), "Evalution of a web-based introductory psychology course: I. learning and satisfaction in on-line versus lecture courses", Behavior Research Methods, Instruments \& Computers, Vol. 32 No. 2, pp. 230-239.

Mason, R. (2002), "E-learning: what have we learnt?", in Rust, C. (Ed.), Proceedings of the 9th International Symposium of Improving Student Learning: Improving Student Learning Using Learning Technology, Oxford Centre for Staff and Learning Development, Oxford, pp. 27-34.

Mason, R., and Rennie, F. (2006), Elearning: the key concepts. Routledge, London.

McConnell, D. (2002), “The experience of collaborative assessment in e-learning”, Studies in Continuing Education, Vol. 24 No. 1, pp. 73-92.

MacDonald, J. (2004), "Developing competent e-learners: the role of assessment", Assessment \& Evaluation in Higher Education, Vol. 29 No. 2, pp. 215-226.

McDonald, J. (2006), “The role of e-teaching in e-learning. Who's learning? Whose technology?", in Markauskaite, L., Goodyear, P. and Reimann, P. (Ed.), Proceedings of the 23rd annual conference of the Australasian Society for Computers in Learning in Tertiary Education, 3-6 December 2006, University of Sydney, Australia, Sydney University Press, Sydney, pp. 529-533. 
McGill, L., Nicol, D., Littlejohn, A., Grierson, H., Juster, N. and Ion, W.J. (2005), “Creating an information-rich learning environment to enhance design student learning: challenges and approaches", British Journal of Educational Technology, Vol. 36 No. 4, pp. 629-642.

McPherson, M.A. and Nunes, J.B. (2008), "Critical issues for e-learning delivery: what may seem obvious is not always put into practice”, Journal of Computer Assisted Learning, Vol. 24 No. 6, pp. 1-13.

Moller, L., Foshay, W.R. and Huett, J. (2008), “The evolution of distance education: implications for instructional design on the potential of the Web", TechTrends, Vol. 52 No. 3, pp. 70-75.

Morville, P. (2005), Ambient findability. O'Reilly, Sebastopol.

Nielsen, J. (2000), Designing Web usability. New Riders Publishing, Indianapolis.

Oliver, R. (2002), "Winning the toss and electing to bat: maximising the opportunities of online learning", in Rust, C. (Ed.), Proceedings of the 9th International Symposium of Improving Student Learning: Improving Student Learning Using Learning Technology, Oxford Centre for Staff and Learning Development, Oxford, pp. 35-44.

Paas, F. and Firssova, E. (2004), “Usability evaluation of integrated e-learning”, in Jochem, W., Merriënboer, J.J.G.V. and Koper, R. (Ed.), Integrated e-learning implications for pedagogy, technology and organization, RoutledgeFalmer, London, pp.112-125.

Phipps, L. and Kelly, B. (2006), "Holistic approaches to e-learning accessibility", ALT-J, Research in Learning Technology, Vol. 14 No. 1, pp. 69-78.

Piccoli, G., Ahmad, R. and Ives, B. (2001), "Web-based virtual learning environments: a research framework and a preliminary assessment of effectiveness in basic IT skills training", Management Information Systems Quarterly, Vol. 25 No. 4, pp. 401-426.

Pilkington, R.M. and Walker, S.A. (2004), "Facilitating debate in networked learning: reflecting on online synchronous discussion in higher education”, in Goodyear, P., Banks, S., Hodgson, V. and McConnell, C. (Ed.), Advances in research on networked learning, Kluwer Academic Publishers, Netherlands, pp. 67-90.

Pituch, K.A. and Lee, Y-K. (2006), “The influence of system characteristics on e-learning use”, Computers \& Education, Vol. 47 No. 2, pp. 222-244.

Rhee, C., Moon, J. and Choe, Y. (2006), "Web interface consistency in e-learning”, Online Information Review, Vol. 30 No. 1, pp. 53-69.

Rosenberg, M.J. (2001), E-learning: strategies for delivering knowledge in the digital age. McGraw-Hill Professional, New York.

Ruiz, J.G., Mintzer, M.J. and Leipzig, R.M. (2006), “The impact of e-learning in medical education”, Academic Medicine, Vol. 81 No. 3, pp. 207-212.

Russell, T.L. (2009), No significant difference phenomenon, available at: http://nosignificantdifference.wcet.info/ (accessed 19 April 2009)

Scalise, K., Bernbaum, D., Timms, M., Harrell, S.V., Burmester, K., Kennedy, C.A. and Wilson, M. (2007), "Adaptive technology for e-learning: principles and case studies of an emerging field", Journal of the American Society for Information Science and Technology, Vol. 58 No. 14, pp. 2295-2309.

Schneiderman, B. (1999), Supporting creativity with advanced information-abundant user interface, HumanComputer Interaction Laboratory, Institute for Advanced Computer Studies, University of Maryland, USA, available at: http://www.lib.umd.edu/drum/bitstream/1903/6037/1/TR_99-73.pdf (accessed 31 August 2009)

Sclater, M. and Bolander, K. (2004), "Factors influencing students' orientation to collaboration in networked learning", in Goodyear, P., Banks, S., Hodgson, V. and McConnell, C. (Ed.), Advances in research on networked learning, Kluwer Academic Publishers, Netherlands, pp. 175-203.

Secker, J. (2004), "E-learning and information literacy", in Secker, J. (Ed.), Electronic resources in the virtual learning environment: a guide for librarians, Chandos Publishers, Oxford, available at: http://eprints.lse.ac.uk/4884/1/E-learning_and_information_literacy_(LSERO).pdf (accessed 19 April 2009)

Segers, M., Jan, N. and Gijselaers, W. (2006), "Redesigning a learning and assessment environment: The influence on students' perceptions of assessment demands and their learning strategies", Studies in Educational Evaluation, Vol. 32 No. 3, pp. 223-242. 
Shields, P.M. and Tajalli, H. (2006), "Intermediate theory: the missing link to successful student scholarship", Journal of Public Affairs Education, Vol. 12 No. 3, pp. 313-334.

Stewart, T.M., MacIntyre, W.R., Galea, V.J. and Steel, C.H. (2007), "Enhancing problem-based learning designs with a single e-learning scaffolding tool: two case studies using challenge FRAP”, Interactive Learning Environments, Vol. 15 No. 1, pp. 77-92.

Tavangarian, D., Leypold, M.E., Nölting, K., Röser, M. and Voigt, D. (2004), "Is e-Learning the solution for individual learning?", Electronic Journal of e-Learning, Vol. 2 No. 2, available at: http://www.ejel.org/volume2/vol2-issue2/v2-i2-art4-tavangarian.pdf (accessed 19 April 2009)

Thorpe, M. and Godwin, S. (2006), "Interaction and e-learning: the student experience", Studies in Continuing Education, Vol. 28 No. 3, pp. 203-221.

Trasler, J. (2002), “Effective learning depends on the blend”, Industrial and Commercial Training, Vol. 34 No. 5, 191-195.

Twigg, C.A. (1999), Improving learning \& reducing costs: redesigning large-enrolment courses. National Center for Academic Transformation, Saratoga Springs, available at: http://www.thencat.org/Monographs/mono1.pdf (accessed 19 April 2009)

Twigg, C.A. (2001), Innovations in online learning: moving beyond no significant difference. National Center for Academic Transformation, Saratoga Springs, available at: http://www.center.rpi.edu/Monographs/Mono4.pdf (accessed 19 April 2009)

Wagner, D.G. and Berger, J. (1985), "Do sociological theories grow?”, The American Journal of Sociology, Vol. 90 No. 4, pp. 697-728.

Wang, K.H., Wang, T.H., Wang, W.L. and Huang, S.C. (2006), "Learning styles and formative assessment strategy: enhancing student achievement in Web-based learning", Journal of Computer Assisted Learning, Vol. 22 No. 3, pp. 207-217.

Wang, Y-M. (2007), "Riding to the future - an investigation of information literacy skills of students at an urban university as applied to the Web environment", International Journal of E-learning, Vol. 6 No. 4, pp. 593-603.

Waterhouse, S. (2005), The power of elearning: the essential guide for teaching in the digital age. Pearson Education, Inc., Boston.

Webb, E., Jones, A., Barker, P. and Schaik, P. van. (2004), "Using e-learning dialogues in higher education", Innovations in Education and Teaching International, Vol. 41 No. 1, pp. 93-104.

Wegner, S.B., Holloway, K.C. and Garton, E.M. (1999), “The effects of internet-base instruction on student learning", Journal of Asynchronous Learning Networks, Vol. 3 No. 2, available at: http://www.sloanc.org/publications/jaln/v3n2/pdf/v3n2_wegner.pdf (accessed 19 April 2009)

Zhang, D. (2005), "Interactive multimedia-based e-learning: a study of effectiveness", The American Journal of Distance Education, Vol. 19 No. 3, pp. 149-162. 


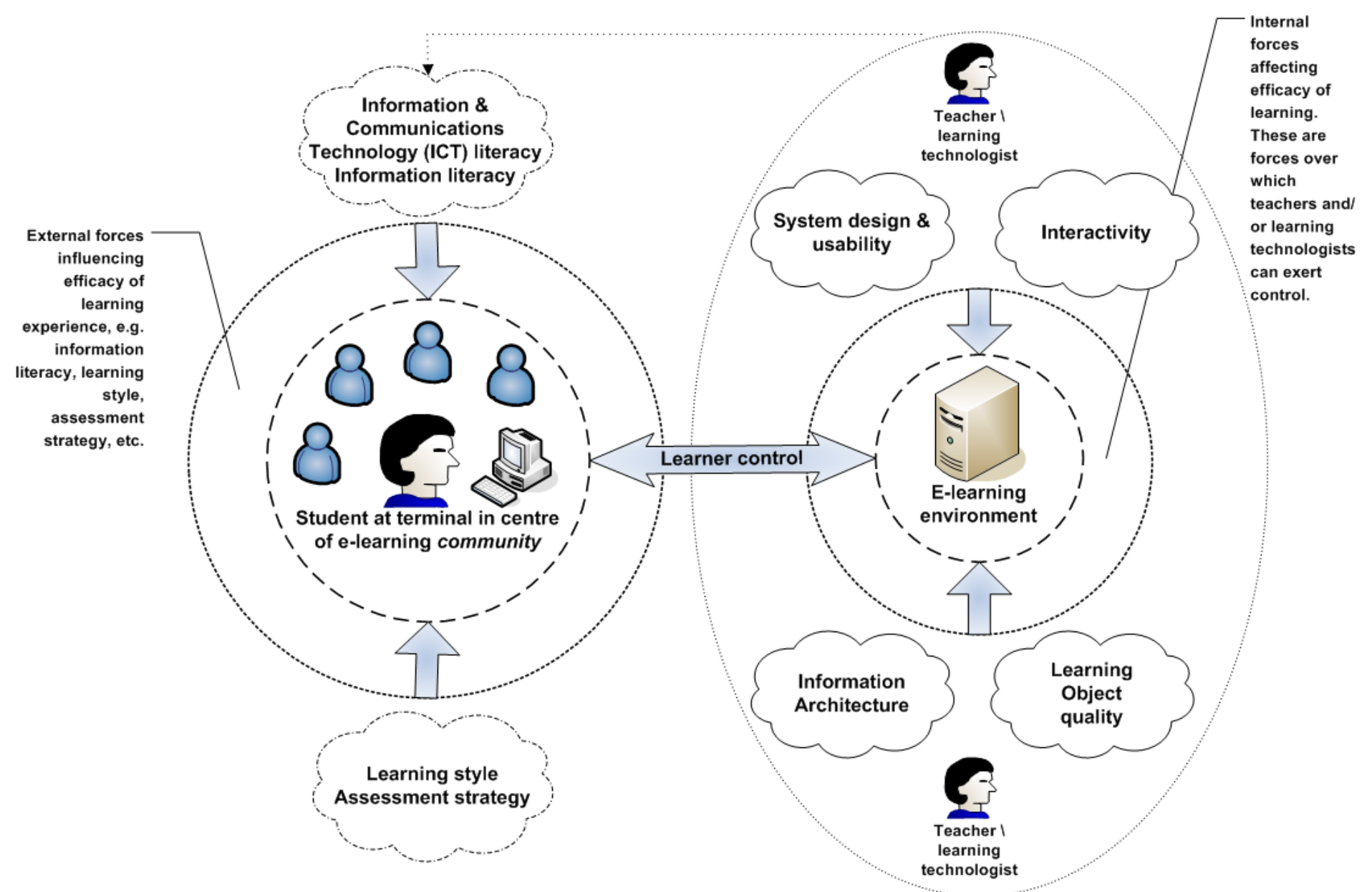

Figure 1: Conceptual model of factors in e-learning effectiveness. 


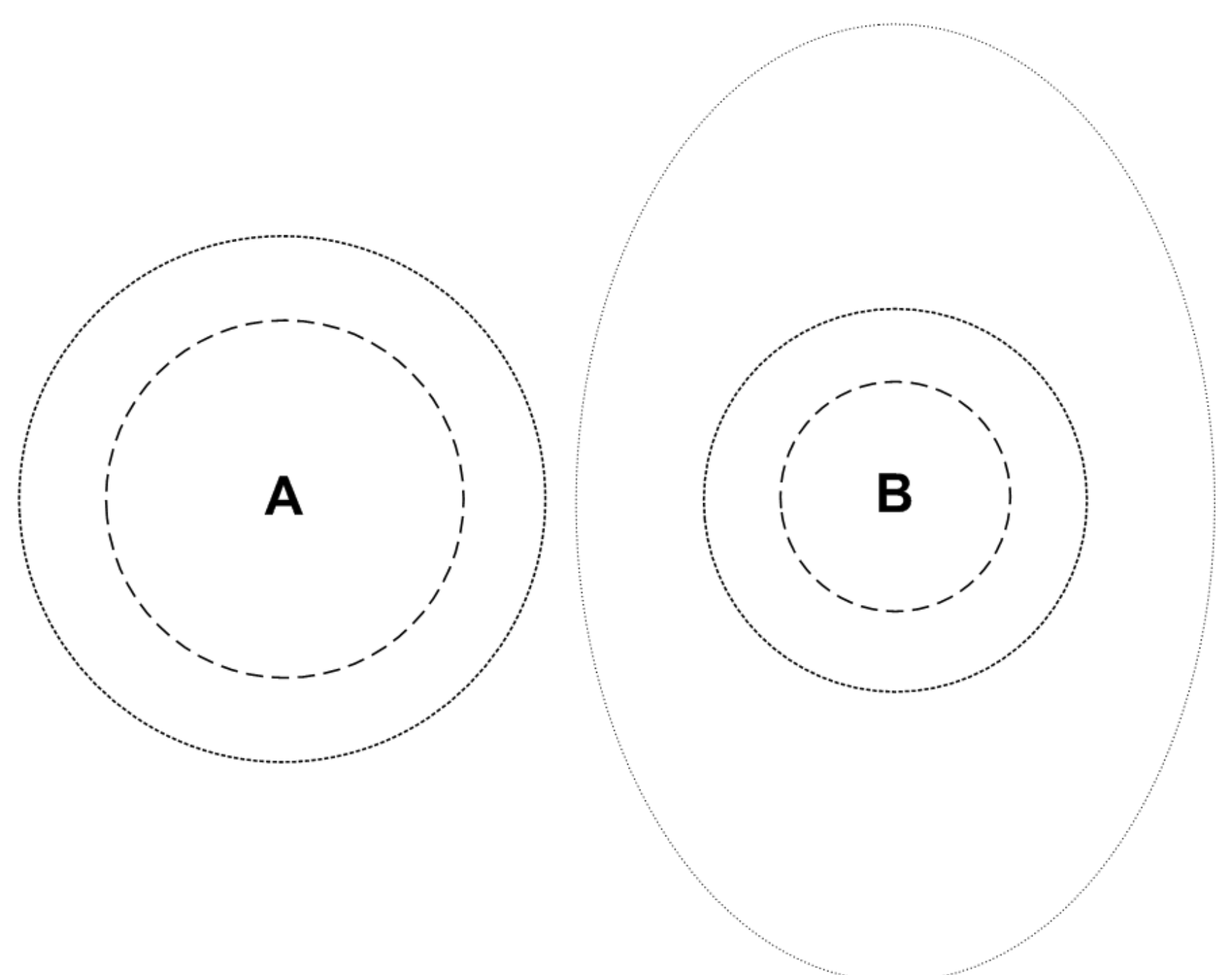

Figure 2: Main nodes of the conceptual model, connected in Figure 1 by 'learner control'. 